\title{
Innovating Through Structured Curriculum Development
}

Catherine Sutton-Brady, University of Sydney, Australia

Nicole Stegemann, University of Western Sydney, Australia

\begin{abstract}
Structured and innovative curriculum development can have a profound impact on learning outcomes. This paper provides interesting and innovative ideas for educators in higher education institutions to allow them to achieve improved learning outcomes. This paper showcases how engaging students throughout the course and supporting them through consistent, incremental course development leads to innovative curriculum development. The improved course structure and students' increased engagement achieve maximum learning outcomes. Various research studies support the use of innovative methods though not much is said about consistency of assessments and course structure in curriculum development with the aim to reduce exam anxiety and ultimately enhance learning outcomes. In our unit of study, seminar presentations and poster sessions in conference style were used to engage students and introduce them to a different way of learning other than reports. The paper not only provides information for educators on how to design engaging course structures but more significantly supports the outcomes through the analysis of student feedback based on objective teaching evaluation conducted before exams.
\end{abstract}

Keywords: Curriculum development, Innovation, interactive exams, poster sessions

\section{INTRODUCTION}

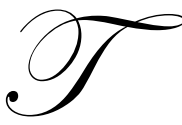

his paper introduces a structured innovative approach to curriculum development, where students are engaged throughout the course and also supported through consistent, incremental course development. The improved course structure and students' increased engagement achieve maximum learning outcomes. Various research studies support the use of innovative methods though not much is said about consistency of assessments and course structure in curriculum development with the aim to reduce exam anxiety and ultimately enhance learning outcomes. The development takes place in a final year elective unit at a University in Australia, the unit is entitled Markets of Europe. This unit aims to introduce students to the member states of the European Union in terms of their marketing environment, with emphasis on those various features, similarities, differences and interactions deemed to be of commercial and marketing significance. A major focus of the course will be the impact of European integration and the relevance of the European Union. The European Union will be discussed in its global context, particularly its relationship with Central and Eastern Europe and the Asia-Pacific. The course therefore gives students the opportunity to undertake macro-environmental analysis and examine the effects of environmental influences on marketing, while also learning about other cultures. (UWS Handbook 2008)

To achieve the aims of the course seminar presentations and poster sessions in conference style were used to engage students and introduce them to a different way of learning other than reports. The paper not only provides information for educators on how to design engaging course structures but more significantly supports the outcomes through the analysis of student feedback based on objective teaching evaluation conducted before exams.

The paper begins by reviewing the literature on curriculum development and innovation in assessments. It then provides an overview of the implementation of the curriculum change and presents the outline of a typical 13 week semester. It presents the findings based on student feedback and concludes by highlighting the main outcomes of the curriculum change and innovation. 


\section{CURRICULUM DEVELOPMENT}

Based on our objectives we reviewed the existing literature on assessment and curriculum development. This allowed us to make more informed choices of how to develop the curriculum effectively and what assessments methods to use to achieve our objectives.

One of the first questions with curriculum development or change is why is change necessary? (Clarke and Christie, 1995) Therefore before making any change educators must have clear objectives for the change and a structured implementation plan. Previous researchers have shown that implementing change can be exceptionally effective if done in a logical and systematic manner (Sutton-Brady and Stegemann, 2006). In line with this systematic approach researchers have noted that curriculum development should not happen too fast as this would lead to superficial change (Sng, 2008).

Much work has been undertaken in the need for aligning curricula with professional competencies required of graduates (Rowley and Slack, 2000). Other authors have looked specifically at the need for innovation in curriculum design (Roffe, 1997). Roffe (1997) discusses the notion of curriculum development being a cycle which requires the institution to provide the impetus for change and development. We would argue that impetus can be provided by the coordinator of the subject who can take the leadership role based on their area of specialisation and experience. Indeed the important role of the academic is curriculum development has been well researched (Rowley et al, 1997).

Another interesting factor in considering curriculum development is the incremental nature of the development of assessment and learning (MacDonald et al, 2000). This idea of incremental learning ties in to some extent with the constructivist approach to learning (Cooperstein and Kocevar-Weidinger, 2004). In effect incremental assessment is designed in such a way that it builds on previous work throughout the semester. The constructivist approach takes us beyond this, in that in addition to building on prior knowledge learning is further enhanced by social interactions. It is active learning where students can interact and learn from each other, while undertaking authentic tasks. These authentic tasks are those considered closest to real-life (Cooperstein and Kocevar-Weidinger, 2004).

With these ideas on curriculum development our aim was to find the assessment tasks which would allow us to improve the learning outcomes while developing a more effective curriculum design.

\section{ASSESSMENT REGIME}

In terms of curriculum development essentially in this subject we were searching for ways for students to achieve the learning outcomes in a challenging non- intimidating manner. It is well documented that a major challenge in curriculum design is the effective assessment of the learning outcomes of the subject. Assessment methods in business schools around the world have involved various forms of assessment. Multiple choice tests, short answer tests, essay tests, cases, projects, presentations and simulations have all been part of the assessment mix (Hartley et al 2002). Most educators in an attempt to assess the learning outcomes most effectively have used a mix of these methods. Much researcher has been undertaken investigating the effectiveness of the methods (Bacon 2003). While these traditional methods have proved successful in many curricula, educators have attempted to promote innovative assessment approaches in order to successfully improve student learning and engage students in the learning experience more deeply (Pearce and Sutton-Brady ,2003; Stegemann and Sutton-Brady 2006 and Sutton-Brady 2006).

The first assessment is the seminar presentation, these seminar presentations will be explained in more detail in the implementation section, but overall the idea is to utilise peer teaching, giving students a sense of ownership of the subject and its' assessment. Peer teaching is common at many universities and in many faculties, although its' effectiveness is not often measured (McIlveed, Grennan and Humphreys, 1997). Mcllveed et al (1997) also comment on how peer teaching gives students a more active role in managing their learning and makes them more flexible creative thinkers who can transfer their learning. 
Additionally in previous research by the authors they found the use of poster sessions to be highly effective in improving learning outcomes (Stegemann and Sutton-Brady 2007). The use of poster session in education is nothing new and has been used for years especially in science related fields using poster sessions instead of presentations for students is commonplace. The research on poster sessions highlights this assessment task as a good alternative which is seen as a more effective learning tool than presentations because students feel more comfortable with the concept (Mills et al 2000). Many authors claim the benefits of poster sessions as being numerous including that poster sessions were a more enjoyable experience for the students, developed research and critical thinking skills, promoted communications skills), encouraged creativity increased enthusiasm, promoted collaborative learning and encouraged independent thought (Dunstan and Bassinger; 1997 Grace 2003; Sisak 1997; Wimpfheimer 2004) . Poster sessions get students more involved in the subject matter and allow them achieve a deeper level of understanding and as a result they become active learners (Huddle 2000).

What is really great about poster sessions is the somewhat less formal setting than presentations. Many authors comment that the most critical questions come from the other students and the format gives students a clear opportunity to sharpen their questioning and critical thinking skills in this less formal more interactive way. This clearly helps to build an informal and relaxed learning environment where students can in a sense socialise with others and in line with the constructivist approach learning is further enhanced by social interactions.

The following section will highlight our constructivist approach in implementing the curriculum change.

\section{IMPLEMENTATION}

As part of curriculum development a number of sequenced teaching and assessment components have been implemented. The first class starts off with a seminar topic presented by the lecturer and a teamwork activity, in which students get to know each other. The second class includes another seminar presentation by the lecturer and a practice session on how to create a poster. These exercises are complemented through student seminar presentations, two poster presentations and the subject concludes with an exam. This scaffold approach allows the students to be introduced to unfamiliar assessment tasks such as the poster session and helps to build a more structured learning environment whilst ensuring the familiarity allows for a relaxed environment

The subject is run as a 3 hour seminar over 13 weeks. In the first class, students are introduced to the class format as well as the teaching and assessment components for the subject. An introductory seminar in specified topic areas is presented. The main focus of this class is to set the objectives for the subject and create an interactive and relaxed learning environment. Therefore, the seminar presentation contains interactive components such as short video clips on Europe, a short knowledge test identifying European countries, as well as some general questions on Europe. The seminar is followed by a teamwork activity for which students form groups and evaluate each others work. At the end of the class, each group receives a list of materials to be brought to the following class; these include colored pens, scissors, glue, collage materials as well as international magazines.

The second class also starts off with a seminar presentation and is followed by a practice poster building exercise to introduce students to this kind of unfamiliar assessment component. Each group is then provided with an A1 sheet and asked to define 'International Marketing' in a visual format, using the materials they have brought to class. After 45 minutes, students display their posters and are invited to critically evaluate each others posters. During the third class, students are shown various foreign video clips with an emphasis on the differences in various environmental factors such as culture, political and legal aspects, etc. Students are asked to highlight these differences and to apply them to strategic decision making processes.

Weeks 4 to 7 and 9 to 11 are reserved for student seminar presentations. The students only receive the topic two weeks before their presentation; this allows for fairness in preparation time for all students and is close to reality, given that they are then working on close deadlines. Students are expected to use up-to-date secondary data. Overall the aim is for students to increase their presentation skills, while fostering an open learning environment. It also leads to increased engagement in class and between class members and increases attendance rates. 
Weeks 8 and 12 are set aside for 2 Poster Presentations and peer and lecturer evaluation of the poster. This aims to foster strategic thinking and critical evaluation and analysis. Building on all of this the exam in Week 13 replicates assessment components built up in class. This has the aim of reducing exam anxiety through known structures and formats and the interactivity of the exam creates a more relaxed environment.

The overall objective of this constructivist approach is to build a proper team environment not one where students turn up listen to the lecturer and never get to know each other as they tend hang out in their little groups. Through this interactive approach students build friendships and their learning is enhanced by the social interaction.

\section{ASSESSMENTS GUIDELINES}

In Tables 1 and 2 are excerpts of what the students receive with regard to the assessment tasks in this subject. For more details on the poster session and guidelines associated with it, see Stegemann and Sutton-Brady, 2007. Clear guidelines are considered extremely important when introducing new assessment tasks, especially when those tasks are innovative in nature and not totally in line with what students are traditionally used to (Stegemann and Sutton-Brady, 2006)

In implementing this assessment regime the key to making it work is providing students with clear guidelines to assessment and prompt feedback on work completed. In order to allow for students to learn from their submitted and completed work, extensive feedback is given within a week. This quick process provides students with the opportunity to improve their work and/or receive reassurance. In order to be able to provide fast and objective feedback for assessments standards based marking guides are used. The key to success in changing an assessment regime and making changes to the curriculum is student involvement in the process, if students feel that they change is not being imposed on them and that they are in fact part of the change process they feel more comfortable with new assessment tasks

\section{INTERACTIVE EXAM FORMAT}

The final exam is an individual exam worth $50 \%$ of the total assessment for this subject. It consists of three parts worth 35\%, 25\% and 40\% respectively. Part A relates to the group project (poster topic) and tests the soundness of the recommended marketing strategies. Part B tests evaluation skills and critical thinking skills. Students have to critically evaluate a poster they have previously not seen. Part C relates to the seminar discussions and tests their knowledge of what has been presented in class, they have to answer two out of three essay questions.

We will explain the interactive exam, since this is a rather novel approach and not one we have not found any specific literature on. The students receive ten minutes reading time and three hours writing time. During writing time, students can decide the order of answering questions. For question B, students will have to get up and evaluate one of three posters, which are attached to a wall and are unknown them to them. There is one group of three posters for each group of 30 students. In other words for a class size of 60 students, there will be two areas with three posters each.

Students are not allowed to communicate with each other in any form. Also, no extra materials are allowed. The interactivity arises from the fact that the students are allowed to move around during the exam to look at the posters and find their own rhythm. They find it easy to find their comfort zone and the atmosphere is more relaxed.

Our objective in using this exam format was to create the relaxed atmosphere. Much research exists on the issue of examination anxiety and its impact on examination performance (Martin 1997; Musch and Broder 1999; Cassaday et al 2002; Roney et al 2003, Stegemann and Sutton-Brady 2006). Cassaday et al (2002) in particular, highlight how raised anxiety levels impact on performance but note that a relaxed environment can reduce anxiety 
Table 1: Guidelines on Poster Session

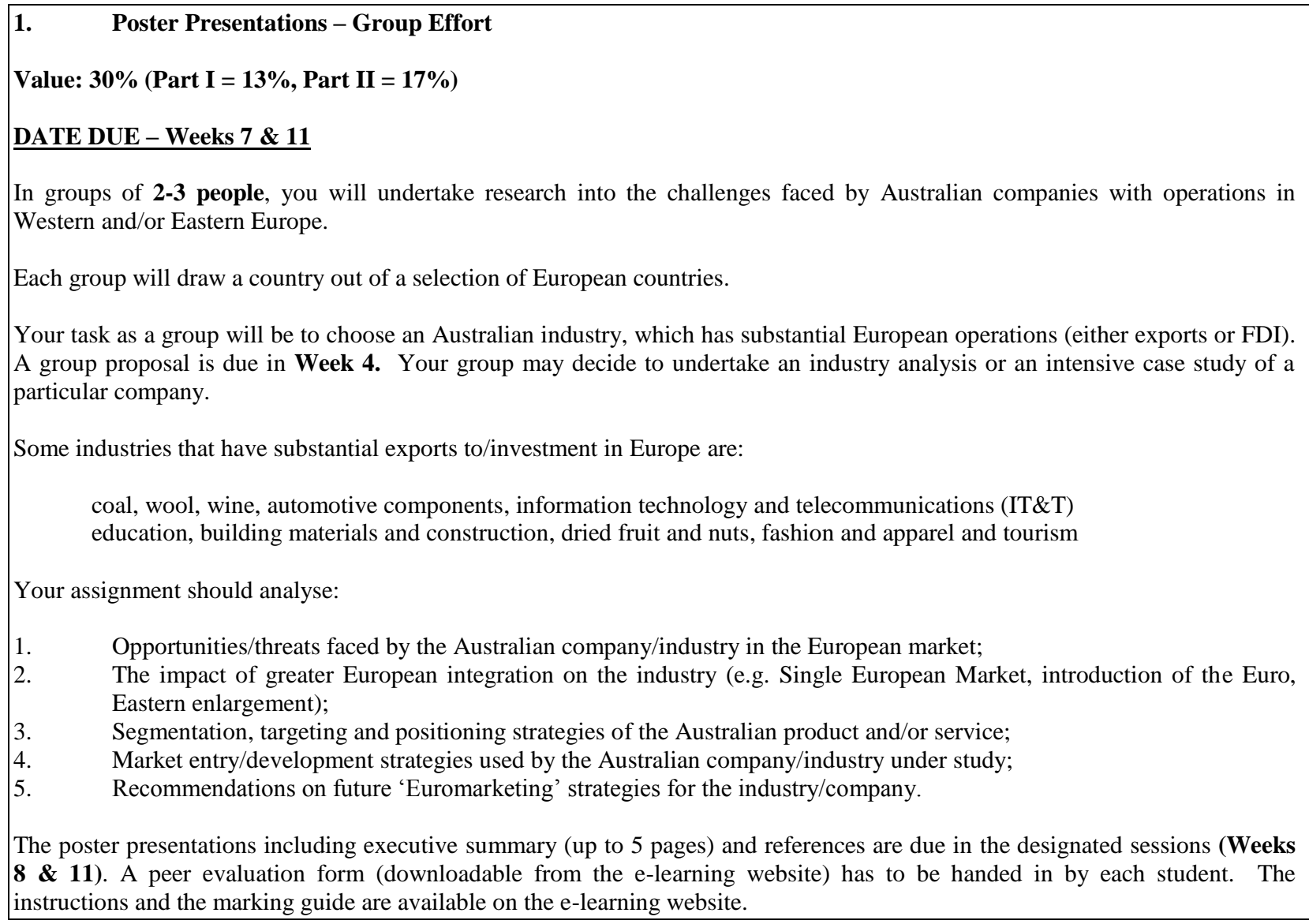

Table 2: Guidelines on Seminar Presentation

\section{Seminar Presentation - Individual/Group Effort}

Value: $20 \%$ (Individual Effort 15\%, group effort 5\%)

\section{DATE DUE - Weeks 3 to 10}

This is a research assignment, which requires students to undertake independent research to pass this assessment component. Students who do not show evidence of independent research will fail.

Individual seminar topics will be assigned to groups in week 1. Each seminar topic contains a set of questions, which have to be answered individually. The set of questions will be made available to groups on the e-learning website two weeks before presentations are due.

Although the majority of the marks will be awarded to individual presentation performance, $5 \%$ will be awarded for the group working together cohesively. The key is that the individual presentations don't overlap. In order to achieve 5\%, the group must have worked together to achieve a seamless presentation. The individual students will not be penalised for poor performance of individual members. The marking guide is available on the e-learning website.

Groups have to submit a hard copy and electronic copy of PowerPoint presentation including a reference list of all sources used. A copy of the presentation and reference list will be uploaded to the e-learning website, and made available to all students. 


\section{FINDINGS}

Our findings are based on formal student feedback gathered through objective university run evaluations of the subject. 60 students completed the evaluations and our findings are based on the comments from their forms. They are clustered into themes that emerged from the student's comments and support our initial objectives. Our main objectives in developing a structured approach to curriculum development were to provide a relaxed atmosphere to reduce anxiety, to provide innovation in the assessment tasks, to ensure increased student engagement and to use a constructive approach to the design of the curriculum.

Supporting our objective of providing innovative assessment, students commented on how it was different from other subjects, how they were able to learn and think in a different way and present their work in a different way. Some direct comments from the students when asked to note the best aspects of the course were:

"The creative assessments different from anything else done previously"

"Poster and exam were very different, but easier to learn from"

"Learning in a different way"

"Different methods of teaching and presenting"

"Doing assessments using visual aids"

"Being able to express our ideas in the form of poster presentation"

"Innovative nature, different from other assignments with the poster which was good for a change"

The next thing we looked at was student engagement and our aim was to achieve this through the interactive nature of the class. It is very clear from the comments that we achieved our aims here. Again the following comments are what students considered the best aspects of this subject:

"Very interactive and entertaining"

"Fun learning environment"

"Poster allowed interaction with all students"

"Interactivity and learning with other students"

"The interactive class held my interest and I learnt more"

In addition to the aspect of interactivity and engagement many students commented on the relaxed and friendly atmosphere of the class. The non-threatening atmosphere that we had aimed to achieve was based on the comments obviously successful. Many discussed the relaxed atmosphere of the exam and poster presentations.

"The open environment in the exam and poster session was friendly"

"Created a friendly atmosphere which makes you feel more comfortable and allows you to learn"

"A more enjoyable experience because of how the class was structured"

"The poster presentations and exam atmosphere were a really nice change allowing friendships to be made in class; I would say this was as a result of the different teaching structure"

Outcomes of our constructive approach to the development of the curriculum change are not as easy to see in the student feedback, it would perhaps be prudent in coming semesters to test for this specifically. However we can glean some notion of success by looking at some comments. Students did talk about structure, the practice poster session and especially the feedback they were given and how that allowed them to build their knowledge, so our feeling overall is that we did achieve our aim in this approach.

"It is very different from most subjects as it incorporates most aspects of class into assessments making it a good tight subject"

"Immediate feedback on assessments allowed us to make improvements"

"Continual guidance and encouragement"

"Constructive feedback with no wait"

"Structure was fair not too much work at once but built on through the semester" 
Finally one thing to come from the feedback that we had not envisioned was how students felt about creativity and the importance of that in their learning experience.

"The creativity used in this subject encouraged a broader learning experience"

"The poster sessions were extremely valuable as in-depth research was required as well as creativity"

"The poster was a creative and interesting way to learn"

"Students were able to express their creative nature, I wish more subjects in my degree gave students a chance to express their creativity"

So based on our findings overall we feel our objectives were achieved.

\section{CONCLUSION}

Our findings show that you can totally change the structure of a subject and be successful, especially in terms of student outcomes. Students clearly enjoy and learn more through innovative methods. Student engagement creates an open interactive environment where they feel they can learn more. This engagement also leads to a friendlier more relaxed atmosphere in the classroom for the presentations and for the exam, which again allows students to perform to the best of their abilities. It is also interesting to note from our findings that students value creativity and the ability to express their creative nature.

Previous research has shown that caution must be exercised, because while students are clearly open to adaptation in assessment and examinations, it must be introduced to them in a thorough and logical way (Stegemann and Sutton-Brady, 2006). It is noted by others that one of the main problems in improving quality of outcomes is motivating the students to take on more responsibility, mainly because many students don't like challenges and prefer the passivity which has dominated higher education (McIlveed et al, 1997). However by using a constructive approach to curriculum development we managed to overcome these challenges. Providing students with clear guidelines, running a practise poster session and providing constructive feedback throughout allowed us to achieve our aims.

Future research will look at investigating in more detail the constructive approach to curriculum development and constructive alignment of the assessment with learning outcomes. However we feel this paper has made a valuable contribution to the literature in this area by showing that your objectives can be achieved through a structured innovative approach to curriculum development.

\section{AUTHOR INFORMATION}

Catherine Sutton-Brady is a senior lecturer in marketing in the Faculty of Economics and Business at the University of Sydney. She holds an MBS from University College Cork, Ireland and was awarded her PhD from the University of Western Sydney in Australia. Her research interests lie in the area of international marketing, business to business marketing and marketing education. She has published articles in Journal of Business Research, Assessment and evaluation in Higher Education, Journal of College Teaching and Learning, College Teaching Methods and Styles Journal and Journal of Business and Economics research. She has also presented papers at many international conferences and invited seminars. In 2006 Catherine was awarded the Pearson Education Australia New Zealand Marketing Academy Marketing Educator of the Year Award.

Nicole Stegemann is a lecturer for the School of Marketing at the University of Western Sydney. She holds a double Masters degree in Business Administration and Economics with specialisations in Marketing and Financial Accounting and Controlling. Her research interests are in the area of luxury brand management, experiential shopping behaviour, consumer relationship management and marketing communications in visual arts. Her current Doctoral research examines the influence of brand extensions on the brand equity of luxury brands. Nicole has published articles in Journal of Business and Economics Research and The Journal of College Teaching and Learning as well as International Business and Economics Research Journal. Her publication record also includes various international conference papers as well as national and international seminar invites. 


\section{REFERENCES}

1. Bacon, D.R. (2003) "Assessing learning outcomes: A comparison of multiple-choice and short-answer questions in a marketing context" Journal of Marketing Education, Vol. 25, No. 1 p.31-36.

2. Cassaday, H.J., Bloomfield, R.E. and Hayward, N. (2002) "Relaxed conditions can provide memory cues in both undergraduate and primary school children," British Journal of Educational Psychology, Vol. 72, p. 513-547.

3. Clarke, P. and Christie, T. (1995) "Assessment-led curriculum development in action: a study of the responses of seven primary schools to statutory requirements" The International Journal of Education Management, Vol.9 No. 4 pp.19-26.

4. Cooperstein, S.E. and Kocevar-Weidinger, E. (2004) "Beyond active learning: a constructivist approach to learning” Reference Service Review, Vol. 32 No. 2. pp. 141-148.

5. Dunstan, M. and Bassinger, P. (1997) "An Innovative Model: Undergraduate Poster Sessions by Health Professional Majors as a method for Communicating Chemistry in Context", Journal of Chemical

Education, Vol. 74, No. 9.

6. $\quad$ Grace, M. (2003) "Poster sessions", Teaching Pre K-8, Vol. 33, No. 6.

7. Hartley, S.W., Cross, J. and Rudelius, W. (2000) "Assessment issues in marketing education. Proceedings of the Western Marketing Educator's Association, edited by Katrin R. Harich and Stuart Van Auken, Lake Tahoe, N.V. as cited in Bacon, D.R. (2003) "Assessing learning outcomes: A comparison of multiplechoice and short-answer questions in a marketing context" Journal of Marketing Education, Vol. 25, No. 1 p.31-36.

8. Huddle, P.A. (2000) “A Poster Session in Organic Chemistry that Markedly Enhanced Student Learning”, Journal of Chemical Education, Vol. 77, No. 9.

9. MacDonald, M.C., Rathemacher, A. J. and Burkhardt, J.M. (2000) "Challenges in building an incremental, multi-year information literacy plan”, Reference Service Review, Vol. 28 No. 3. pp. 240-247.

10. McIlveed, H., Grennan, K. and Humphreys, P. (1997) "Involving students in teaching and learning: a necessary evil?" Quality Assurance in Education, Vol. 5, No. 4. pp.231-238.

11. Pearce, G. \& Sutton-Brady, C. (2003) "International Business Theatre (IBT): An alternative assessment method for enhancing student learning in International Marketing" Assessment \& Evaluation in Higher Education, Vol. 28, No.1, pp.3-15.

12. Roffe, I. (1997) "Developing a dynamic in a learning innovation" Quality Assurance in Education, Vol. 5, No. 2. pp.90-96.

13. Rowley, J. and Slack, F. (2000) "The Star Trek phenomenon: towards a typology of curricula in information management” The International Journal of Education Management, Vol.14 No. 6 pp.276-284.

14. Sisak, M.E. (1997) "Poster Sessions as a Learning Technique", Journal of Chemical Education, Vol. 74, No. 9.

15. Sng, Bee,Bee (2008) "Surface or deep change? How is a curriculum change implemented at ground level" The International Journal of Education Management, Vol.22 No. 1 pp.90-106.

16. Sutton-Brady, C. (2006) "Innovation in Assessment: Injecting Reality into Business Education" Journal of College Teaching and Learning Vol.3 No.10

17. Sutton-Brady, C. and Stegemann, N. (2006) "A Colourful Approach to reducing examination anxiety", Journal of College Teaching and Learning. Vol. 3, No. 1, pp.1-9.

18. Stegemann N and Sutton-Brady C (2007) "Innovative assessment design: The Poster Session", European Teaching and Learning Conference, Venice Italy, June.

19. UWS Handbook (2008) http://handbook.uws.edu.au/hbook/

20. Wimpfheimer, T. (2004) "Peer-Evaluated Poster Sessions: An Alternative method to Grading General chemistry Laboratory Work", Journal of Chemical Education, Vol. 81, No. 12. 